\title{
SOSIALISASI DAN PENGAJARAN TENTANG PENGGUNAAN BAHASA INDONESIA YANG BAIK DAN BENAR BERDASARKAN ETIKA KESANTUNAN BERBAHASA PADA ANAK DIDIK DI YAYASAN TANAH BINTANG DESA KERANDANGAN KECAMATAN BATU LAYAR LOMBOK BARAT
}

\author{
Ahyati Kurniamala Niswariyana ${ }^{1)}$, Titin Untari'), Supratman'), Linda Ayu Darmurtika ${ }^{1)}$, \\ Arpan Islami Bilal ${ }^{1)}$ \\ 1)Prodi Pendidikan Bahasa Indonesia, FKIP, Universitas Muhammadiyah Mataram, Mataram, NTB, Indonesia \\ Corresponding author: Ahyati Kurniamala Niswariyana1 \\ E-mail : aludragisel@gmail.com
}

Diterima 10 November 2020, Direvisi 20 November 2020, Disetujui 20 November 2020

\begin{abstract}
ABSTRAK
Para siswa yang belajar di Yayasan Tanah Bintang merupakan siswa yang ingin belajar ekstra. Siswasiswa tersebut pagi hari belajar di sekolah formal, sore hari belajar bahasa asing dan kerajinan tangan di yayasan. Untuk pembelajaran bahasa, bahasa Indonesia digunakan sebagai bahasa pengantar sebab guru dan siswa adalah penutur bahasa Indonesia sekaligus pembelajar bahasa asing. Pada saat berinteraksi di kelas, para siswa menggunakan bahasa Indonesia nonformal, jauh dari kata benar. Pelaksanaan pengabdian ini memiliki tujuan agar para siswa dapat mengenal bahasanya sendiri sebelum mempelajari bahasa asing, hal ini juga akan berdampak pada pengenalan bahasa Indonesia yang baik dan benar pada warga asing yang tengah belajar bahasa Indonesia. Sehingga bahasa Indonesia yang digunakan tidak merujuk pada bahasa kontemporer atau bahasa gaul, akan tetapi mengacu pada kaidah bahasa Indonesia yang baik dan benar, yakni bahasa lisan yang dapat dipahami lawan bicara serta tidak menyinggung yang sesuai dengan etika berbahasa, dan bahasa tulis yang memiliki acuan jelas yakni PUEBI dan KBBI. Kegiatan pengabdian yang berlangsung selama 4 kali pertemuan ini dinilai berhasil, peserta mengalami kemajuan dari pengetahuan tentang bahasa yang baik dan benar. Hasil akhir yang tampak adalah bahwa peserta mulai memahami perbedaan Bahasa yang baik dan Bahasa yang benar, serta penempatannya dalam berkomunikasi dan menulis.
\end{abstract}

Kata kunci: pembelajaran; bahasa indonesia; baik dan benar

\begin{abstract}
The students of Tanah Bintang Fondation are those who want to have extra learning. Beside studying formally at school, they also learn about foreign language and handicrafts at the foundation. In language learning, Indonesian Language is used as an instruction since teachers and students are the native speakers while studying foreign language. During classroom activity, students usually use non-formal Indonesian which is unstandardized. That is the reason of this devotion, in order to help students to comprehend and understand their Indonesian firstly before learning other foreign languages. It is also aimed at impacting foreigners vice versa to learn Indonesian correctly as standardized. Therefore, the use of Indonesian will refer to Official Indonesian Spelling System rather than slang and contemporary language. The use in spoken language must be understood by interlocutors and should not offend the language etiquette . Other, in written language must be based on PUEBI and KBBI references. The four times meeting devotional has successful to take place due to the enhanced knowledge about the use of correct language itself. The result is participants now has been able to differentiate between standard and unstandard language use both in speaking and writing.
\end{abstract}

Keywords: learning; Indonesian language; good and right

\section{PENDAHULUAN}

Perkembangan bahasa akhir-akhir ini semakin pesat, sejalan dengan perkembangan teknologi yang semakin maju. Era 4.0 menuntut manusia untuk tetap kreatif dan senantiasa berinovasi dalam berbagai bidang, termasuk dalam berbahasa. Bermunculannya bahasa-bahasa kontemporer adalah bentuk kreatifitas masyarakat untuk tetap "eksis" dalam berkomunikasi.

Perkembangan bahasa modern cukup mempengaruhi etika berbahasa seseorang. Orang-orang tidak lagi mengindahkan ramburambu berbahasa. Bahasa-bahasa kontemporer yang dibuat sedikit banyak menyimpang dari aturan yang telah dibakukan. 
Anak-anak sekarang jauh dari kata paham, bagaimana sesungguhnya aturan bahasa, terutama Bahasa Indonesia yang baku.

Negara Indonesia sebagai sebuah negara yang besar yang terdiri dari beribu pulau, memiliki standarisasi dalam penggunaan bahasa, sering kita dengar dengan istilah bahasa baku. Dalam perkembangannya Bahasa Indonesia memiliki tingkatan yakni bahasa kuno, bahasa modern, dan bahasa kontemporer. Bahasa kuno atau bahasa lama dalam komunikasi cenderung menggunakan bahasa baku. Oleh sebab perkembangan bahasa yang kian dinamis, maka bahasa kuno dianggap tak relevan lagi dengan perkembangan zaman, masyarakat modern mulai menyederhanakan bahasa lama tersebut baik dalam tulisan maupun lisan. Menilik perkembangan bahasa modern atau bahasa baru yang kian berinovasi, dikhawatirkan bahasa Indonesia mengalami perubahan yang sangat signifikan, akhirnya para pendiri bangsa menetapkan rambu-rambu kebahasaan yang diatur dengan kaidah-kaidah ketatabahasaan bahasa Indonesia, yang kita kenal dengan Pedoman Umum Ejaan yang Disempurnakan serta Kamus Besar Bahasa Indonesia, yang telah pula mengalami proses pembaharuan dengan nama Pedoman Umum Ejaan Bahasa Indonesia dan Kamus Umum Bahasa Indonesia. Hal tersebut menjadi aturan tertulis yang wajib dipatuhi oleh pengguna bahasa Indonesia dalam berkomunikasi dalam lingkup formal. Dalam situasi nonformal, bahasa kontemporer memegang kendali utama, terlebih dikalangan generasi millenial.

Generasi millenial cenderung
mengabaikan aturan-aturan berbahasa yang ada. Mereka lebih bangga berkomunikasi dengan bahasa asing dibanding dengan bahasa Indonesia. Di kalangan kaum muda, bahasa Indonesia tidak lagi menempati posisi "tuan rumah" di negeri sendiri. Hal ini menjadi catatan kami sebagai pemerhati bahasa Indonesia. Berdasarkan kegelisahan di atas, maka tim kami tergerak untuk mensosialisasikan penggunaan bahasa indonesia yang baik dan benar, yang mana selama ini diketahui hanya jargon pada masyarakat bahasa terutama lingkungan para pemerhati bahasa Indonesia. Harapan kami setelah pengabdian ini, para siswa di Yayasan Tanah Bintang mampu mengaplikasikan penggunaan bahasa Indonesia yang baik dan benar baik secara lisan maupun tulisan. Mengingat Yayasan Tanah Bintang merupakan yayasan yang dikelola oleh warga Jerman yang bergerak di bidang pendidikan dan lingkungan. Letak yayasan yang berada di pusat wisata Lombok juga sangat mendukung tujuan program ini. Hal ini pula yang mendasari keinginan kami untuk mensosialisasikan penggunaan bahasa Indonesia yang baik dan benar, sekaligus sebagai ajang memperkenalkan bahasa Indonesia dengan konteks kebahasaan yang sebenarnya. Hal ini akan berdampak pada perkembangan bahasa Indonesia pada masyarakat setempat juga dapat memperkenalkan bahasa Indonesia yang baik dan benar pada warga asing yang tengah belajar bahasa Indonesia di lingkungan tersebut. Adapun tujuan kegiatan Pengabdian Kepada Masyarakat ini adalah untuk memberikan sosialisasi dan pengajaran penggunaan Bahasa Indonesia yang baik dan benar kepada setiap peserta didik yang sedang belajar pada Yayasan Tanah Bintang. Lebih jauh tujuan sosialisasi ini, guna memperkenalkan Bahasa Indonesia kepada penutur Bahasa Asing yang berada di lingkungan sekitar Yayasan Tanah Bintang, melalui perantara siswa didik Yayasan tersebut.

\section{METODE}

Berdasarkan tujuan di atas, kegiatan pengabdian pada masyarakat yang dilakukan di Yayasan Tanah Bintang Desa Kerandangan Kecamatan Batu Layar Kabupaten Lombok Barat dengan para siswa sebagai mitra kegiatan. Pengabdian tersebut berlangsung selama 7 pekan, dimulai awal maret hingga april 2020. Pelatihan ini dilaksanakan pada tiap hari kamis, yang dimulai pukul 14.00-16.30 Wita. Jumlah peserta pelatihan sebanyak 20 orang yang terdiri dari siswa yang tergabung dalam kelas rendah dan kelas tinggi. Adapun Metode yang digunakan pada saat pembelajaran adalah sebagai berikut (1) di awal Tim Pengabdian melakukan sosialisasi/ pengenalan singkat pentingnya penggunaan Bahasa Indonesia; (2) masuk ke pengajaran inti; (3) dan terakhir evaluasi. Pada saat sosialisasi dan pengajaran, kami menggunakan metode ceramah, dengan memberikan contohcontoh sederhana, selanjutnya kami meminta siswa untuk berdiskusi dengan temantemannya, dan terakhir kami memberikan tugas tertulis, yakni membuat kalimat efektif (kalimat yang benar menurut tatanan Bahasa Indonesia) dan berbicara menggunakan Bahasa yang baik dan santun.

\section{HASIL DAN PEMBAHASAN}

Sebelum memulai pelatihan, tim terlebih dahulu melakukan sosialisasi dan komunikasi dengan pihak yayasan, seperti dan penanggung jawab yayasan, guna kelancaran kegiatan pengabdian. Sosialisasi ini dilaksanakan pada hari jumat, 1 mei 2020. 
Pihak yayasan mendukung penuh rencana kegiatan pelatihan yang akan dilaksanakan. Setelah memperoleh izin dari pihak yayasan, tim kemudian melakukan observasi tentang kondisi awal di lapangan serta wawancara dengan guru pengajar kelas rendah terkait halhal yang akan dibahas pada saat kegiatan pengabdian. Dari hasil observasi dan wawancara dengan guru, ditemukan persoalan bahwa rata-rata siswa tidak memahami Bahasa Indonesia yang baik dan benar, terlebih berkomunikasi dengan Bahasa Indonesia yang baik dan benar. Berikut adalah gambar depan Yayasan yang kami ambil pada saat kedatangan untuk observasi.

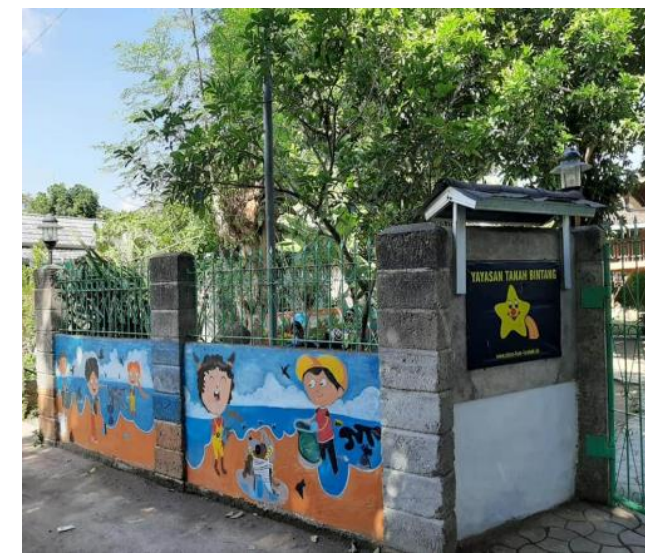

Gambar 1. Gambar depan Yayasan Tanah Bintang.

Setelah melakukan sosialisasi dan observasi keadaan awal, tim kemudian membuat materi sosialisasi dan pengajaran tentang penggunaan Bahasa Indonesia yang baik dan benar serta menyusun pelaksanaan kegiatan. Kegiatan pengabdian dilaksanakan selama 4 kali pertemuan. Setiap pertemuan dilaksanakan sekali dalam sepekan, yakni pada hari selasa. Penyusunan jadwal pengabdian disesuaikan dengan jadwal sekolah siswa kelas rendah di Yayasan Tanah Bintang. Hal ini bertujuan agar siswa datang sesuai jadwal sekolah serta tidak mengganggu kelas lain pada hari berbeda.

\section{Sosialisasi dan Pengajaran tentang Penggunaan Bahasa Indonesia yang Baik dan Benar pada Siswa di Yayasan Tanah Bintang}

Yayasan Tanah Bintang merupakan Yayasan yang ada di Desa Kerandangan. Yayasan Tanah Bintang terletak di jalan pariwisata Desa Kerandangan Kecamatan Batu Layar Kabupaten Lombok Barat, Nusa Tenggara Barat. Dalam proses belajar mengajar, yayasan tersebut menerapkan pola pembelajaran nonformal yang disesuaikan dengan materi ajar siswa pada sekolah formal.
Para siswa lebih intens diajarkan keterampilan guna melatih kemandirian mereka. Hal lain yang diajarkan di sana adalah Bahasa, terutama Bahasa Inggris dan Bahasa Jerman. Para siswa diajarkan Bahasa Inggris sebab daerah lingkungan tinggal mereka merupakan daerah pariwisata, diajarkan Bahasa Jerman sebab yayasan tersebut merupakan yayasan yang didirikan oleh orang Jerman. Bahasa Indonesia tidak diajarkan, sebab pengelola yayasan menganggap para siswa yang notabene merupakan warga Indonesia sudah pasti paham dalam berkomunikasi dengan Bahasa Indonesia. Pada kenyataannya tidak demikian, para siswa berkomunikasi dengan Bahasa Indonesia yang tidak baik dan benar.

Dalam kegiatan tersebut, peserta yang mengikuti pelatihan berjumlah 20 orang yang terdiri atas siswa kelas rendah. Berdasarkan paparan sebelumnya, pelatihan ini dilaksanakan selama 4 kali pertemuan. Adapun rincian kegiatan tiap-tiap pertemuan akan dipaparkan sebagai berikut.

a. Pertemuan I

Pertemuan I dilaksanakan pada hari selasa, tanggal 5 mei 2020. Pada pertemuan I, kegiatan dimulai pada pukul 14.00 Wita. Pertemuan pertama diawali dengan, tim menguji pengetahuan peserta terkait bahasa yang baik dan benar. Hal ini penting untuk menetahui sejauh mana keberhasilan sebuah pengajaran. Selanjutnya tim melaksanakan sosialisasi pengenalan Bahasa Indonesia baik dan tidak baik, benar dan tidak benar, serta perbedaan keduanya. Penyampaian materi ini penting karena memberikan pengetahuan awal tentang bagaimana dan hal-hal apa saja yang harus dipahami sebelum mengaplikasikannya di masyarakat.

b. Pertemuan II

Pada pertemuan II, selasa, 12 mei 2020 pukul 14.00-16.00 Wita, dilaksanakan pengajaran tentang bahasa yang baik serta pengaplikasiannya dalam bentuk komunikasi. Kegiatan ini bertujuan untuk memberikan soft skill pada peserta yang nanti dikemudian hari dapat digunakan sebagi bekal di masyarakat.

Pada pelaksanaannya, tim pelaksana pengabdian memberikan contoh berbahasa yang baik kepada peserta. Selanjutnya tim pengabdian meminta kepada peserta untuk memberikan contoh komunikasi yang baik. Metode ini dilakukan untuk melatih keberanian peserta baik dalam berkomunikasi dengan Bahasa Indonesia yang baik di masyarakat. Di akhir pertemuan, tim pengabdian dengan peserta melakukan evaluasi dan refleksi terkait dengan kegiatan pelatihan pada hari tersebut. 


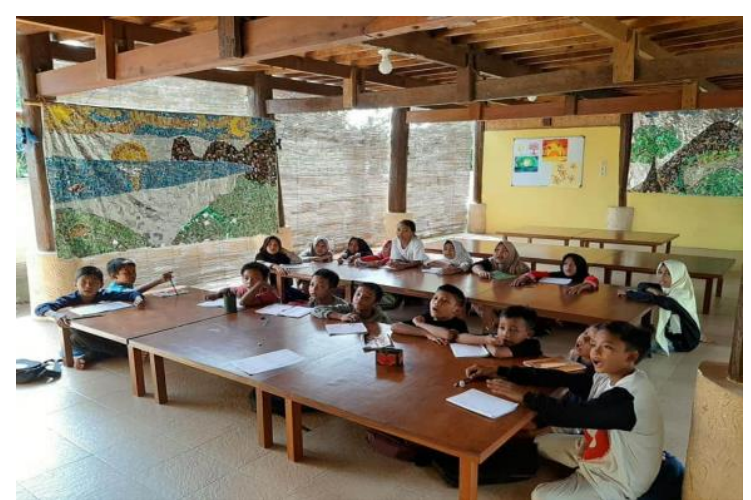

Gambar 2. Pengenalan pembelajaran Bahasa Indonesia yang baik (aplikasi pada komunikasi).

\section{c. Pertemuan III}

Pertemuan III dilaksanakan pada tanggal 19 Mei 2020. Waktu pelaksanaan kegiatan ini sama dengan pertemuanpertemuan sebelumnya yaitu dimulai pada pukul 14.00-16.00 Wita. Materi pelatihan pertemuan III yaitu tentang pengajaran Bahasa yang benar. Tim memberikan contoh penulisan kalimat efektif yang selanjutnya disebut kalimat yang benar. Selanjutnya tim meminta peserta untuk membuat kalimat-kalimat efektif, merangkai kalimat-kalimat tersebut menjadi cerita pengalaman. Selanjutnya tim memeriksa hasil tulisan peserta. Di akhir pertemuan, tim bersama dengan peserta melakukan refleksi dari hasil kegiatan tersebut.

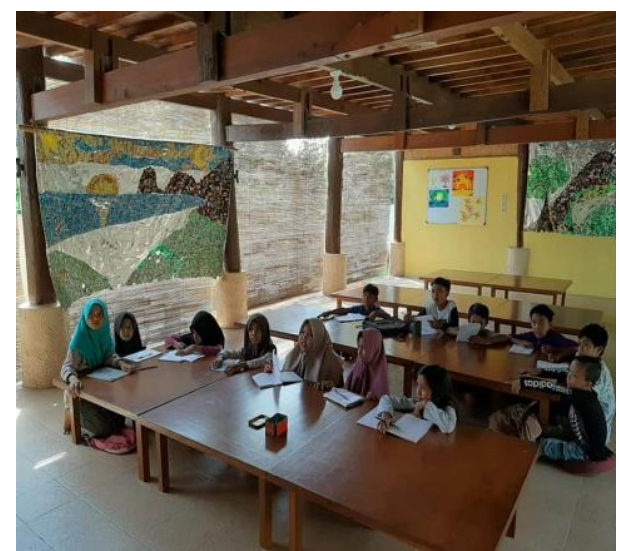

Gambar 3. Pengenalan pembelajaran Bahasa Indonesia yang benar (aplikasi pada Bahasa tulis).

\section{d. Pertemuan IV}

Pelaksanaan pertemuan IV. Pertemuan IV yang sekaligus merupakan pertemuan terakhir dilaksanakan pada hari selasa, $26 \mathrm{Mei}$ 2020 pukul 14.00-16.00 Wita. Tim melaksanakan evaluasi akhir pada peserta pengabdian tentang pemahamannya mengenai Bahasa Indonesia yang baik dan benar. Hasil akhir yang tampak adalah bahwa peserta mulai memahami perbedaan Bahasa yang baik dan Bahasa yang benar, serta penempatannya dalam berkomunikasi dan menulis. Akan tetapi masih ditemukan kesalahan pada tulisan peserta saat menulis kalimat yang benar. Hal ini dirasa wajar, sebab pertemuan yang singkat dan penyampaian materi yang ringkas membuat peserta sedikit kesulitan dalam membedakan kalimat yang baik dan benar pada tulisan.

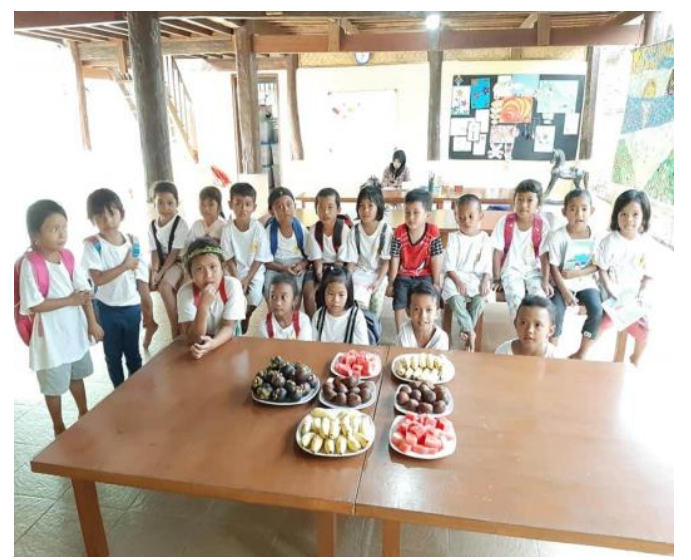

Gambar 4. Di akhir pembelajaran siswa makan buah bersama.

\section{SIMPULAN DAN SARAN Simpulan}

Kegiatan pengabdian yang berlangsung selama 4 kali pertemuan ini dinilai berhasil, peserta mengalami kemajuan dari pengetahuan peserta tentang bahasa yang baik dan benar yang selama ini mereka pahami. Hasil akhir yang tampak adalah bahwa peserta mulai memahami perbedaan Bahasa yang baik dan Bahasa yang benar, serta penempatannya dalam berkomunikasi dan menulis. Akan tetapi masih ditemukan kesalahan pada tulisan peserta saat menulis kalimat yang benar. Hal ini dirasa wajar, sebab pertemuan yang singkat dan penyampaian materi yang ringkas membuat peserta sedikit kesulitan dalam membedakan kalimat yang baik dan benar pada tulisan.

\section{Saran}

Tim merasa perlu untuk melaksanakan pengabdian lanjutan, untuk memberikan waktu lebih banyak pada peserta melakukan tanya jawab mengenai Bahasa Indonesia yang baik dan benar, sehingga peserta tidak keliru dalam mengaplikasikan ilmu yang didapat di masyarakat. Hal lain yang diharapkan adalah peserta pengabdian sebagai perpanjangan informasi sosialisasi Bahasa Indonesia yang baik dan benar pada masyarakat setempat dan pada wisatawan asing yang sedang belajar Bahasa Indonesia. 


\section{UCAPAN TERIMAKASIH}

Ucapan terima kasih kami kepada semua pihak baik yang terlibat secara langsung maupun tidak lagsung dalam kegiatan Pengabdian Kepada Masyarakat ini: 1)Rektor Universitas Muhammadiyah Mataram, 2)Dekan FKIP Universitas Muhammadiyah Mataram, 3)Direktur Yayasan Tanah Bintang, 4)Rekanrekan yang terlibat dalam pengabdian, 5)Staf Yayasan Tanah Bintang dan 6) Para siswa binaan Yayasan Tanah Bintang

\section{DAFTAR RUJUKAN}

Bahri, S. (2018). FENOMENA KEDWIBAHASAAN DI SEKOLAH DASAR; SEBUAH KONDISI DAN BENTUK KESANTUNAN BERBAHASA. Jurnal Bidang Pendidikan Dasar. https://doi.org/10.21067/jbpd.v2i2.2649

Gusriani, N., Tamazaki, \& Ratna, E. (2012). Kesantunan Berbahasa Guru Bahasa Indonesia dalam Proses Belajar Mengajar di SMA Negeri 2 Lintau Buo. Jurnal Pendidikan Bahasa Dan Sastra Indonesia.

Gustiasari, D. R. (2018). Pengaruh Perkembangan Zaman Terhadap Pergeseran Tata Bahasa Indonesia ; Studi Kasus Pada Pengguna Instagram Tahun 2018. Jurnal Renaissance.

Hidayah, N. (2015). Penanaman Nilai-nilai Karakter dalam Pembelajaran Bahasa Indonesia di Sekolah Dasar. Jurnal Pendidikan Dan Pembelajaran Dasar.

Ivan Lanin. (2016). Bahasa Indonesia yang Baik dan Benar. Beritaagar.

Leksono, M. L. (2019). Analisis Kesalahan Penggunaan Pedoman Ejaan Bahasa Indonesia (PUEBI) Pada Tugas Makalah dan Laporan Praktikum Mahasiswa IT Telkom Purwokerto. JP-BSI (Jurnal Pendidikan Bahasa Dan Sastra Indonesia). https://doi.org/10.26737/jpbsi.v4i2.1106

Malutin, M. (2018). TINDAK TUTUR DALAM PEMBELAJARAN BAHASA INDONESIA SISWA KELAS X DI MA UNGGULAN ALKAUTSAR TROWULAN MOJOKERTO TAHUN PELAJARAN 2015/2016. MATAPENA: Jurnal Keilmuan Bahasa, Sastra, Dan Pengajarannya.

Mansyur, U. (2016). Inovasi Pembelajaran Bahasa Indonesia melalui Pendekatan Proses. Retorika: Jurnal Bahasa, Sastra, Dan Pengajarannya. https://doi.org/10.26858/retorika.v9i2.380 6

Muzaki, A., Chadis, C., \& Agustin, Y. (2019). Pengenalan Pedoman Umum Ejaan Bahasa Indonesa (PUEBI) dalam Mengembangkan

Kemampuan
Berbahasa Indonesia yang Baik dan Benar bagi para Guru. Jurnal PkM Pengabdian Kepada Masyarakat. https://doi.org/10.30998/jurnalpkm.v2i02. 3202

PUEBI. (2016). Pedoman Umum Ejaan Bahasa Indonesi. In Pedoman Umum Ejaan Bahasa Indonesi.

Rahayu, A. P. (2015). Menumbuhkan Bahasa Indonesia yang Baik dan Benar dalam Pendidikan dan Pengajaran. Jurnal Paradigma.

Sabaryati, Johri., Isnaini, M., Darmayanti, N.W. S., Utami, Linda Sekar., Niswariyana, A. K. (2019). Pelatihan Spreadsheet untuk Media Pembelajaran Kreatif dan Solutif bagi Siswa SMA/MA di Kecamatan Narmada. SELAPARANG: Jurnal Pengabdian Masyarakat Berkemajuan, 2(2), 28-32.

Utami, S. (2017). PEMBELAJARAN ASPEK TATA BAHASA DALAM BUKU PELAJARAN BAHASA INDONESIA. AKSIS: Jurnal Pendidikan Bahasa Dan Sastra Indonesia. https://doi.org/10.21009/aksis.010203 